\title{
Helices of disaster memory: How forgetting and remembering influence tropical cyclone response in Mauritius
}

\author{
Rory A. Walshe ${ }^{1 *}$, George C.D. Adamson ${ }^{2}$, Ilan Kelman ${ }^{3,4}$ \\ ${ }^{1}$ Department of Geography, University of Cambridge, UK \\ ${ }^{2}$ Department of Geography, King's College London, UK \\ ${ }^{3}$ Institute for Risk and Disaster Reduction and Institute for Global Health, University College London, UK \\ ${ }^{4}$ University of Agder, Kristiansand, Norway \\ * Corresponding author Rory Walshe, email rw647@cam.ac.uk
}

\section{Abstract}

Tropical cyclones have had a considerable impact on Mauritius. Large cyclones are relatively rare, and in popular imagination are thought to hit Mauritius every 15 years. Yet it has been over 25 years since the last cyclone widely considered as 'significant'. Critically, there is little known about the role of memory in responses to cyclones and details regarding responses to past cyclones in Mauritian history are scant.

This article examines past experiences and impacts of cyclones in Mauritius, as well as contemporary perceptions of cyclone vulnerability and memories of historical cyclones. The analysis draws on both community interviews and archival research conducted in Mauritius and takes a longue durée approach. This apporach combines an examination of both event and process with historical discourses in an effort to uncover the long-standing and slowly changing relationships between people and extreme events.

The results reveal a number of repetitive patterns of responses that act out over the long term and repeat for many of the largest cyclones, indicating that tropical cyclone impact and recovery in Mauritius is strongly conditioned by complex, cultural, and place based memory (and forgetting). While these patterns could be characterised as cycles, the research instead presents a concept of 'helices' as a new conceptualisation of long term disaster memory patterns. This research is part of a growing literature arguing for the need to account for the historical processes fundamental to understanding vulnerability. This has implications for disaster risk reduction (including climate change adaptation) in Mauritius, other small islands, and elsewhere.

Key words: Tropical Cyclones, Mauritius, Memory, Disaster Risk Reduction, Vulnerability 


\section{Introduction}

Foundational disaster studies literature from the 1970s and 1980s established that disasters are products of natural hazards interacting with human-made vulnerability (Ball, 1979; Dynes, 1975; Hewitt, 1983; O'Keefe et al., 1976; White, 1974; Wisner, 1993). Despite disasters often being presented as 'natural', they are, in fact, anything but, and should instead be understood as a result of the actions, decisions and structures people live with. In order to reduce disasters, there is a need to understand the causes and drivers of human vulnerability. This is not a simple task. Social science research has repeatedly demonstrated that human vulnerability is multifaceted, culturally complex (Bankoff et al., 2015; Krüger et al., 2015), and develops and acts out over the long term (Endfield, 2007; Garcia-Acosta, 2007). Consequently, disaster research must account for the long-term and historical processes that create vulnerability (Adamson et al., 2018; Bankoff, 2004; Endfield, 2012). Research investigating the role of history in disasters has developed significantly over the last twenty years (García-Acosta, 2017; OliverSmith, 1996; Schenk, 2007, p. 9), although direct empirical data are still relatively rare, partly due to disciplinary separation between historians and contemporary disaster researchers.

A historical lens can uncover, as Schenk (2015) argues, a level of structural knowledge about disasters which can be used to clarify the far-reaching and long-term social mechanisms, processes and structures for dealing with disaster. Such research can thus uncover 'trajectories' in vulnerability and resilience over time (Bankoff, 2007; Barclay et al., 2019; Fazey et al., 2011; Hicks and Few, 2015), and challenge the view that changes in disaster magnitude and frequency are caused by more natural hazards (GarciaAcosta, 2007). While great care should be taken in drawing direct or linear connections between the deep historical record and the present day (Endfield, 2012), the longue durée offers a reservoir of details about extreme and recurring events like cyclones, including social precursors, impacts and responses, all of which can provide information today for societies experiencing changing hazards (Bankoff, 2004; Glantz, 2003). Longue durée approaches - combining elements of event and process with an analysis of historical discourses (Adamson et al., 2018; García-Acosta, 2017) - can also offer insight into social adaptation processes which unfold across long periods (Adamson et al., 2018; Bankoff, 2004; Glantz, 1988).

By illustrating the long term development of vulnerability, a historical perspective can also position extreme weather as relative to other factors, natural processes and climate change impacts and patterns, uncovering common root vulnerabilities (Hewitt, 2014). Therefore, it can be argued that a full and complete understanding of disasters requires a consideration of the longue durée and the historical context in the long term (García-Acosta, 2017). Such historical disaster studies can uncover the various 'pathways' along which many groups, communities and institutions are embarking (Adamson et al., 2018). 
The concepts of pathways and trajectories both aim to map out patterns over time, not unlike the contentious yet enduring 'disaster cycle' that divides up disasters into stages. The disaster cycle is rightly critiqued for its underlying assumption of an automatic return to an original starting point (Manyena, 2012; O'Brien et al., 2010), the concept of a 'normal' state to attain in the first place (Hills, $1998)$ and the clear definition of stages before and after a disaster. As Bankoff (2009, p. 277) notes, the structure and pattern of how disasters and memory operate over time "is neither linear nor circular, but much more an ad hoc evolution based on past events and improvisation" which acts out as a slow gestation over time. In response, this research presents and develops a new 'helical' conceptualisation of patterns in disaster experience and memory over time. The application of the helix shape has been theorised as a replacement to the disaster cycle and a potential way to include an explicit consideration of time in understanding disaster patterns before (Bosher, 2005, p. 13). Yet this concept has not been explored further or tested in practice, and thus this study is the first to apply the idea of the helix shape to empirical evidence of long-term disaster response and vulnerability, and to use it to specifically examine and explain disaster memory and forgetting (and the resulting responses).

This research responds to these gaps in knowledge through a case study of cyclones in Mauritius. Mauritius island $\left(20^{\circ} 10^{\prime} \mathrm{S} 57^{\circ} 31^{\prime} \mathrm{E}\right)$ - located just north of the Tropic of Capricorn, approximately $800 \mathrm{~km}$ west of Madagascar - has been devastated by tropical cyclones at multiple points in its past. Consequently, cyclones have played a considerable role in shaping Mauritian history, from concepts of racial belonging and community (Rouphail, 2020) to agriculture (Rouphail, 2019), and meteorological science (Mahony, 2018). Large cyclones in Mauritius are said to occur infrequently (Vaghjee and Yan, 2003), in popular belief around 15 years apart (see results below). Yet it has been a comparatively long time since the last very damaging cyclone struck Mauritius, considered to be either cyclone Dina in 2002 or Hollanda in 1994.

In examining disaster response in Mauritius over the longue durée, this study is particularly interested in the role of disaster memory in informing vulnerability and cyclone response. Disasters have been documented across all of recorded human history and consequently memory of disasters is likely widespread, since all societies (to varying extents and levels of success) have created cultural ways to deal with disasters, environmental risk and climate throughout their history (Krüger et al., 2015; Nunn, 2018; Taub, 2003; Walshe and Nunn, 2012).

Memory can be understood as an expressive and actively binding process of social identity (Hoelscher and Alderman, 2004: 248). Weather that disrupts the 'normal', such as cyclones, is most likely to become inscribed in memory and news, chronicles or other commemorative forms (Golinski, 2007). The process of creating a weather 'event' in memory is both collective and cultural, since a key moment is the transition (for example in and after a cyclone) from being impacted by simply weather (the 
normative) into the bounded narrative of 'an event'. Groups of people come to terms with and 'stabilise' extreme weather through the cultural inscription of extremes as a discursive and behavioural stabilisation of the extraordinary (Janković and Fleming, 2017). Thus, extreme weather transitions from a tacit part of nature into a 'social and textual reality' through the altering of behaviour and changing of plans. This process of event making creates a socially meaningful referent for different groups to make sense of the experience and deal with its impacts (Endfield and Veale, 2017). Consequently, extreme events, like cyclones, are retrospectively made or produced as much as they are experienced (Oliver-Smith and Hoffman, 1999).

The ways in which both normal and extreme weather are understood, remembered, memorialised and recorded determines how descendants understand risk emergent from those extremes, and how climate - and climate change - is positioned and contextualised (Hall and Endfield, 2016; Lorenzoni and Pidgeon, 2006; Palutikof et al., 2004). A growing literature is also demonstrating the importance of considering the complex long-term processes behind remembering and forgetting past disasters when developing disaster risk reduction (DRR) policies (García-Hernández et al., 2019; Garde-Hansen et al., 2017; McKinnon, 2019; McKinnon and Cook, 2020; Simpson and Corbridge, 2006). However more research is needed, and comparatively speaking, there are still few studies into the memory of extreme events or weather and how this influences vulnerability (Adamson, 2012; Endfield and Veale, 2017; Jones et al., 2012).

Research on cyclone memory specifically is rarer still (notable exceptions being Mock, 2004, 2008, Chenoweth, 2006, 2014; Daniel et al., 1986), including in the Indian Ocean (Garnier and Desarthe, 2013). Rohland (2015) demonstrated the importance of public memory in adaptation and mitigation to hurricanes in $18^{\text {th }}$ and $19^{\text {th }}$ century Louisiana. Mock (2017) provides three classifications of storm memory: persistent memory, intermittent memory and lack of memory. He argues that since cyclone damage is often associated more with settlement patterns than cyclone strength (Hewitt, 2014), the most remembered or persistent cyclones in memory can be associated with high or notable societal impacts within major centres of population (Mock, 2017). Cyclones can also become memorialised when they occur during times of political change, for example the 'great storm' of 1703 in western Europe (Pfister et al., 2010).

As research by Monteil et al. (2020) demonstrates, collective memory can also anchor disasters in the past and not necessarily act as a reminder or warning of risk. Thus memory of disasters in their own right cannot be assumed to be useful. Similarly one important finding from the existing literature is that inter-generational learning from events like tropical cyclones (with high impacts but low frequency) on decadal time scales is not guaranteed (Rohland, 2015, 2018). The variable return periods of large tropical cyclones points to the possibility of a 'disaster gap'; that a long interval between disasters can 
result in at risk populations forgetting their exposure and practices of response (Pfister et al., 2002). Additionally the suppression of disaster memory can be deliberately deployed to serve political agendas (Lewis, 2015; Pfister, 2011). Schenk (2015) has also suggested that modern societies may have a 'blind spot' regarding the memory of disasters in history, potentially due to the current focus (and arguably over-reliance) on techno-centric early warning systems. For this reason, this study is equally as interested in the forgetting of cyclones as in remembering.

This research focuses on the role of cultural memory in how responses to cyclones in Mauritius have changed over time by detailing the patterns of interaction between communities and cyclones and the creation of cyclone disasters. This paper first presents the archive and interview methods used by this research. The paper then highlights three key elements of responses, perceptions, and memory over time: 1) the experience and memory of the cyclone eye, 2) the seasonal timing of cyclones and 3) the perceptions and discourses regarding cyclone frequency. For each, first the archive data are presented to illustrate the historical context, before the corresponding interview data are presented to illustrate the contemporary context. The paper concludes with a discussion of the implications of these results and expands the idea of the helices concept as a framework through which to understand disaster memory and forgetting through time.

\section{Methods}

\subsection{Archive data collection}

This research combines contemporary interviews with substantial archive research in several locations in Mauritius. Archive data collection focused on building a rich descriptive picture of the experience, impact and response to past cyclones. The collection primarily focused on governmental records stored in the National Archive (NA) of Mauritius (Table 1), and newspapers stored in various archives (Table 2), supported by a substantial collection of complementary sources including early scientific books and reports, almanacs, chronicles and histories, personal papers, travelogues, literature, novels and written folklore (detailed separately where cited in footnotes as per convention).

Table 1: Government archive records sampled from the National Archives (NA) of Mauritius

\begin{tabular}{|l|l|l|l|l|}
\hline $\begin{array}{l}\text { Name of collection } \\
\begin{array}{l}\text { Council of } \\
\text { Government debates }\end{array}\end{array}$ & Group & $\begin{array}{l}\text { Catalogue code } \\
\text { Various }\end{array}$ & $\begin{array}{l}\text { Example } \\
B 4 A 1892 \\
V 1\end{array}$ & $\begin{array}{l}\text { Description } \\
\text { Transcripts and proceedings of the governing } \\
\text { debates of council }\end{array}$ \\
\hline $\begin{array}{l}\text { Legislative debates } \\
\text { and ordinances }\end{array}$ & $\mathrm{B}$ & $\begin{array}{l}\text { LC B0 0000 } \\
\text { (year) }\end{array}$ & $\begin{array}{l}\text { LC B7 } \\
1960\end{array}$ & $\begin{array}{l}\text { Ordinances and legislative council transcripts and } \\
\text { public bills }\end{array}$ \\
\hline Dispatches & $\mathrm{R}$ & $\begin{array}{l}\text { SA 000 0000 } \\
\text { (year) }\end{array}$ & $\begin{array}{l}S A 224 \\
1944\end{array}$ & $\begin{array}{l}\text { The response telegrams and dispatches from the } \\
\text { government in Mauritius to the colonial } \\
\text { government }\end{array}$ \\
\hline $\begin{array}{l}\text { Departmental reports } \\
\text { and letters }\end{array}$ & $\begin{array}{l}\mathrm{Z} \\
\mathrm{R}\end{array}$ & $\begin{array}{l}\text { NA group (Z cat.) } \\
\text { HA 00-0 } \\
\text { (department code) }\end{array}$ & $\begin{array}{l}\text { NA HA 17- } \\
\text { Departmental documents, reports, and letters from } \\
\text { departments to centralised government }\end{array}$ \\
\hline
\end{tabular}




\begin{tabular}{|l|l|l|l|l|}
\hline Summary of press & $\mathrm{Z}$ & $\begin{array}{l}\text { SD 000 0000 } \\
\text { (year) }\end{array}$ & $\begin{array}{l}\text { SD 313 } \\
1960\end{array}$ & $\begin{array}{l}\text { Colonial records of press releases and monitoring } \\
\text { of the print media }\end{array}$ \\
\hline Blue Books & B & BB 0000 (year) & BB 1931 & $\begin{array}{l}\text { A single annual report summarising government } \\
\text { departments }\end{array}$ \\
\hline
\end{tabular}

Table 2: Old newspaper records sampled from various archives.

\begin{tabular}{|c|c|c|c|}
\hline Name of Newspaper & $\begin{array}{c}\text { Location } \\
\text { (s) }\end{array}$ & $\begin{array}{l}\text { Date } \\
\text { range }\end{array}$ & Description \\
\hline Le Cernéen & National Library & $\begin{array}{l}1852- \\
1982\end{array}$ & $\begin{array}{l}\text { Francophone daily newspaper, large circulation numbers before } \\
\text { collapse in } 1982 .\end{array}$ \\
\hline Mauritius Times & National Library & $\begin{array}{l}1954- \\
\text { present }\end{array}$ & $\begin{array}{l}\text { Weekly English newspaper published each Friday and now } \\
\text { online. Includes some limited content in French and } \\
\text { international features. }\end{array}$ \\
\hline News on Sunday & National Library & $\begin{array}{l}2002- \\
\text { present }\end{array}$ & $\begin{array}{l}\text { Published weekly (on Sunday) all English, now online at Le } \\
\text { Défi Media Group }\end{array}$ \\
\hline L'Express & National Library & $\begin{array}{l}1963- \\
\text { present }\end{array}$ & $\begin{array}{l}\text { Daily French newspaper with some content in English, now } \\
\text { online. }\end{array}$ \\
\hline $\begin{array}{l}\text { Le Mauricien (and Le } \\
\text { Nouveau Mauriciene) }\end{array}$ & National Library & $\begin{array}{l}1908- \\
\text { present }\end{array}$ & $\begin{array}{l}\text { Daily francophone newspaper, large circulation, some limited } \\
\text { English material. Now online in addition to print copy. }\end{array}$ \\
\hline Week-End & $\begin{array}{l}\text { National Library / } \\
\text { JPC (private } \\
\text { collection) }\end{array}$ & $\begin{array}{l}1908- \\
\text { present }\end{array}$ & $\begin{array}{l}\text { The weekend edition published by Le Mauricien (see above), } \\
\text { mostly in French. }\end{array}$ \\
\hline The Mauritius Gazette & $\begin{array}{l}\text { National Archive / } \\
\text { National Library }\end{array}$ & $\begin{array}{l}\sim 1815- \\
2018\end{array}$ & $\begin{array}{l}\text { Also known as the Mauritius government gazette, irregular } \\
\text { publication, containing updates on official government matters, } \\
\text { laws and policies. English. }\end{array}$ \\
\hline $\begin{array}{l}\text { The Planters and } \\
\text { Commercial Gazette }\end{array}$ & National Archive & $\begin{array}{l}1815- \\
1945\end{array}$ & $\begin{array}{l}\text { The government newspaper, mostly English and from the } \\
\text { perspective of the land owning elite, presenting local notices } \\
\text { and news. }\end{array}$ \\
\hline Gazette des Illes & $\begin{array}{l}\text { Carnegie Library } \\
\text { Curepipe }\end{array}$ & $\begin{array}{l}1986 \\
\text { onwards }\end{array}$ & $\begin{array}{l}\text { Intermittent news magazine that reprints historical newspaper } \\
\text { articles and commentary. }\end{array}$ \\
\hline
\end{tabular}

The sampling of these collections of archive data followed a dual methodology:

A targeted and systematic approach was taken to sample the government records and the old newspapers, designed so as to collect as consistent a record as possible and to ensure that the relevant material was recorded (accepting that certain volumes are damaged or missing). This systematic approach delivered the majority of archive data collected. The systematic approach was adopted for the period 1879 to 2019, chosen because this period offered accessible records, mostly in English, and many of the records from before the middle of the $19^{\text {th }}$ century have deteriorated or are lost. 1879 was chosen as the start date due the occurrence of a large cyclone that year. For the government records this involved systematically searching through all volumes available in the years that 'major' cyclone occurred, starting a month before the cyclone. The designation of a cyclone as 'major' was given if the details of damages and the descriptive passages regarding the cyclone in the archive were judged by the researcher to be equivalent to Beaufort scale ten or above (see MMS, 2016). This was an iterative process, with reassessment of severity as data accumulated. 
Newspaper data collection involved searching through issues available for the cyclone months (November-May) in the same known major cyclone years, and for the six months following the landfall of the cyclone. The selection of which newspapers to analyse was conducted in a pragmatic manner, prioritising papers in English (the authors' mother tongue). Searching through a six month period of issues was not always possible due to the decay of some early newspapers.

A complementary probe approach was adopted for all the archive sources, including the government records and old newspapers. This involved following leads in a 'snowball' manner as suggested by other sources, guided by bibliographies, indexes, citations, and background reading in an opportunistic and pragmatic manner. This approach was particularly intended to collect data regarding the role of memory in the impact of and response to tropical cyclones. Unlike the structured approach, this was not restricted to a specific timeframe since instead it 'probed' into volumes and had the advantage of delivering hidden sources, outside of the known material and the major 'cyclone years'. While this probe approach was used on all types of archive sources it was particularly useful when examining travelogues and personal correspondence.

\subsection{Interviews}

139 semi-structured interviews were conducted in 52 different communities in Mauritius. The selection of communities in which to conduct interviews focused on the smaller, more rural, lower income or subsistence orientated settlements, in order to capture a diverse sample (see table 4) of Mauritians that are suggested to be more vulnerable to the impacts of tropical cyclones. The selection of these locations and this criteria was guided by discussions with local stakeholders involved in DRR, particularly the Red Cross. Note that, as Titz et al. (2018) argue the concept of a 'community' is rarely analysed in research and is often an artificial unit created by external bodies (including researchers) that inadequately accounts for the divisions and internal power structures within, and instead assumes uniform groups in agreement, homogenous and equal (Cannon, 2013). This research therefore makes no assumption of positive shared characteristics in the communities sampled. The location of these communities is shown in figure 1 as well as table 3.

Within the communities themselves participants were sampled using opportunistic snowball sampling, either based on approaching participants on the street or knocking on house doors. The interviews were conducted with a local research assistant who provided translation and helped navigate any cultural dynamics if necessary. The interviews involved a series of questions aimed at gauging how people currently perceive tropical cyclone risk, to what extent memory of past cyclones informs this understanding, and how communities experience the impact, response and adaptation to tropical cyclones in Mauritius, both currently and in the past. This included detailing memories of specific 
historical cyclones, if the respondents had experienced any. Data collection underwent institutional ethical approval through the King's College London clearance procedure.

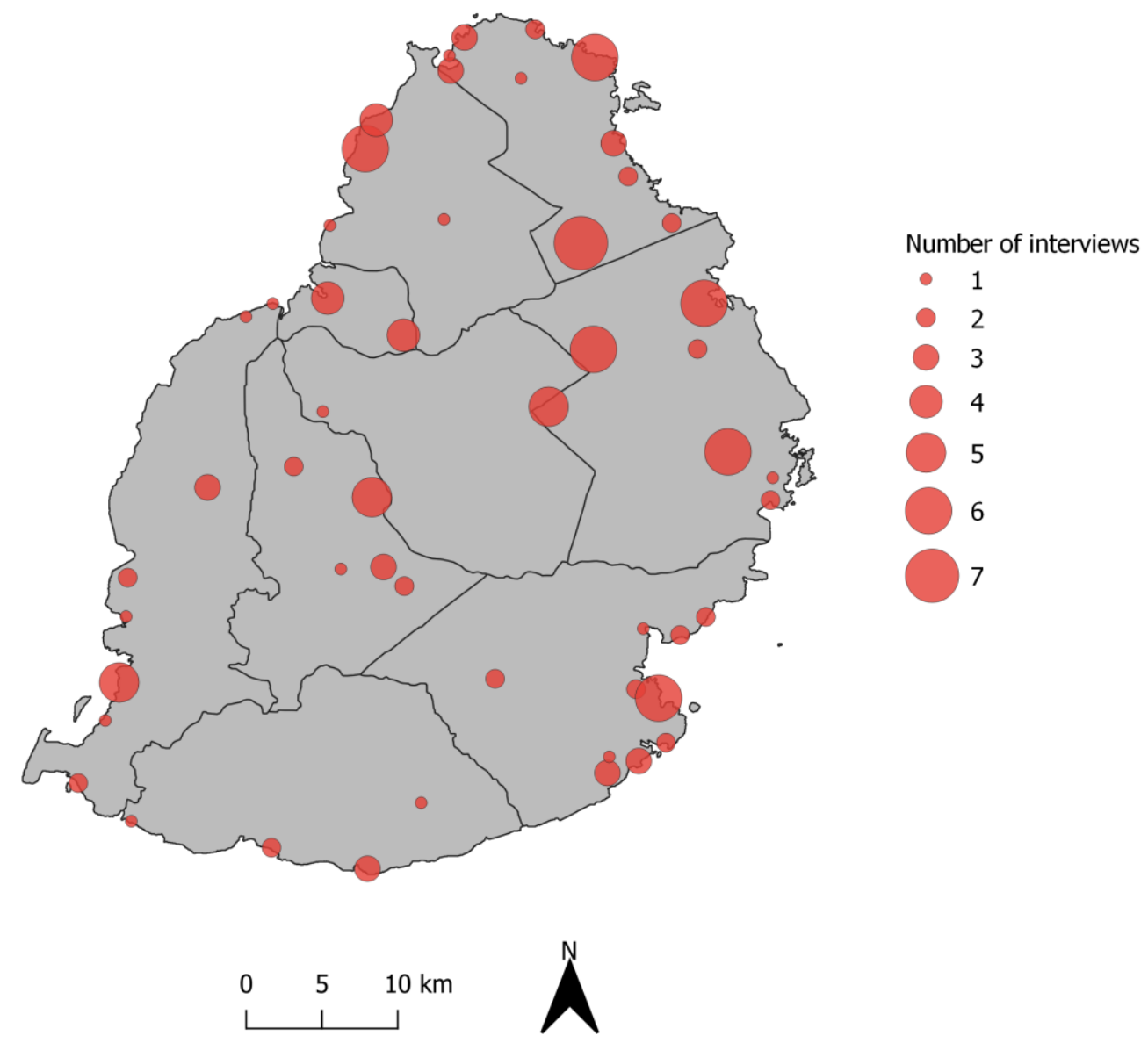

Figure 1: The location of communities sampled with the number of interviews (map by author)

Table 3: The locations of community interviews (in alphabetical order)

\begin{tabular}{|c|c|c|c|c|c|}
\hline Interview Location & No. & Interview Location & No. & Interview Location & No. \\
\hline 16eme mille & 2 & Ferney & 1 & Pointe aux Piment & 6 \\
\hline Anse la Raie & 2 & Grand Baie & 3 & Pointe aux Sables & 1 \\
Argy & 2 & Grand Gaube & 6 & Port Louis & 4 \\
Baie du Cap & 1 & Grand Riviere Noir & 1 & Poste de Flacq & 6 \\
Baie Tombeau & 2 & Grand Riviere SE & 2 & Poudre d'Or & 3 \\
Beau Champ & 1 & La Cambuse & 3 & Quatre Boune & 2 \\
Beau Songe & 3 & La Cuvette & 1 & Reduit & 1 \\
Bel Air & 6 & La Gaulette & 1 & Residence Attee & 1 \\
Belle Vue Maurel & 7 & Lallamatie & 6 & Riviere des Anguilles & 1 \\
Blue Bay & 2 & Le Morne & 2 & Roche Noir & 2 \\
Bois Des Amourettes & 2 & Mahebourg & 6 & Rose Belle & 2 \\
Camp Carol & 3 & Mondessert & 1 & Souillac & 3 \\
Camp Fouquereaux & 5 & Pamplemouses & 1 & St Julien d'Hotman & 5 \\
Camp Le Juge & 3 & Panchavati & 2 & St Malo & 1 \\
Casa Noyale & 5 & Perebere & 3 & Tamarind & 2 \\
Chemin Grenier & 2 & Petit Raffray & 1 & Terrason & 1 \\
Chitrakoot & 4 & Pointe aux Biches & 4 & Vieux Grand Port & 2 \\
\hline & & & Ville Noire & 2 \\
\hline
\end{tabular}


Table 4: Demographics of Interview participants

\begin{tabular}{|c|c|c|c|c|c|}
\hline Gender & No. & Age & No. & Occupation / work sector & No. \\
\hline Male & 86 & $20-29$ & 7 & Construction & 8 \\
\hline \multirow[t]{15}{*}{ Female } & 53 & $30-39$ & 6 & Cook / Chef & 4 \\
\hline & & $40-49$ & 17 & Custodial staff / estate management & 15 \\
\hline & & $50-59$ & 34 & Driver / transport & 5 \\
\hline & & $60-69$ & 44 & Education sector & 8 \\
\hline & & $70-79$ & 26 & Factory & 6 \\
\hline & & $80-89$ & 4 & Farmer (livestock or agriculture) & 16 \\
\hline & & $90-100$ & 1 & Fishing & 11 \\
\hline & & & & Government employee / contactor & 10 \\
\hline & & & & Housewife & 9 \\
\hline & & & & Manual labour & 3 \\
\hline & & & & Other & 6 \\
\hline & & & & Service sector (Inc. tourism) & 16 \\
\hline & & & & Skilled trade & 10 \\
\hline & & & & Student & 3 \\
\hline & & & & Unemployed / no occupation & 8 \\
\hline
\end{tabular}

\section{Results}

The results are presented in relation to three categories: cyclone eye, seasonal timing, and perceptions of frequency. These categories occurred frequently across all of the cyclones analysed, exhibiting recurring patterns of memory and forgetting. Hence these themes highlight the role of memory and history in the responses to and impacts of tropical cyclones in Mauritius. Information relating to each of these categories from archival materials and contemporary memories (where appropriate) are presented chronologically, beginning with the cyclone of 1892. For each category, contemporary perceptions from interviews are then discussed.

\subsection{The cyclone eye}

Mention of a period of relative calm in the eye of the cyclone was found in archival material relating to for 14 cyclones: 1760, 1836, 1840, 1845, 1892, 1897, 1908, 1931, 1944, 1945 (January), 1960 Carol, 1975 Gervaise, 1979 Claudette and 1994 Hollanda. Not all these cyclones experienced full calms, and the descriptions regarding the experience vary considerably, yet a pattern of repetitive forgetting is apparent.

One of the most striking examples of forgetting the characteristics of a cyclone's eye (and the deadly consequences) was during the devastating April 29 1892 cyclone. An absolute lull in cyclonic 
conditions across all areas of the island led to some parts experiencing a calm for four hours; "All at once the wind fell to a dead calm, the rain ceased, and even sunshine brightened the scene", A considerable proportion of people in Mauritius were apparently under the impression that the cyclone was over, as was reported after the cyclone by a correspondent:

"The wind calms its fury, a thick fog, a precursor of good weather, soon envelops us. The lull is perfect, and soon we are completely reassured",2

Based on this misunderstanding, a large number of people took actions during the calm that increased their exposure. For the most part this included people leaving their shelters, either to view the devastation or to begin recovery. For example, as reported in the morning post:

"The wind without warning lulled, the clouds dispersed, and a bright sun shining in a blue sky proclaimed apparently that the tempest had subsided, and that all sense of peril had passed away. People accordingly began to look about, ... Men went, some to business, some outside to see the effects of the storm, thinking all was over,3

Additionally, certain actions that might have reduced the damages were neglected:

"The general population was reassured, and very little thought was given to closing the shutters on the opposite side from where the gusts had come before, 4

"Unfortunately, of the majority of the townspeople who wandered about the streets and, tired of having been shut up for several hours, opened all the large windows and doors,"5

Many archive sources blamed the high death toll of 1,262 fatalities $^{6}$ on this lack of awareness:

"Those who realised the fact [of the return] were able to save themselves. It is greatly to be feared that the majority did not, and that the greater part of the deaths which have been recorded, and the ruin that was produced, is due to this fact",7

\footnotetext{
${ }^{1}$ Mure, A. / 1892 / p16 / the Mauritius Disaster - reprinted from the Standard $11^{\text {th }}$ May / NL

2 The Gazette des îles / 1892 / p17 / CLC

${ }^{3}$ Hamley, W. / 1989 / p28 / The Hurricane in Mauritius - reprinted from the morning post. May $12^{\text {th }} / \mathrm{NL}$

${ }^{4}$ Annals de Union Catholique / 1892 / 17th of May / n16 / National Library

${ }^{5}$ Toussaint / 1936 / p439 / Port-Louis, two centuries of history (1735-1935) / NL

${ }^{6}$ LeBlanc, M. (1892) Une Mauricienne d'Exception / OL; there is some disagreement on the final figure

7 Jerningham / 1892 / p3 - Cyclone of April 29 - reprinted from Blackwood's Magazine, September 1892
} 
Following the 1892 cyclone, several smaller cyclones had partial lulls in conditions including in 1908, 1931 and 1944. Yet these did not match the complete cessation of cyclone conditions of 1892 and the reporting of these events noted that the lulls passed unnoticed by many in Mauritius. Consequently, there was a 53-year gap between the 1892 cyclone and the next comparable central calm crossing the island, between $16^{\text {th }}$ and $17^{\text {th }}$ January 1945 . Media at the time drew direct associations with 1945 ; " 1945 will now be associated in local history with 1892",8. In 1945, just as in 1892, communities once again incorrectly thought the cyclone was over during the passage of the eye:

"The winds died down and it seemed like the cyclone was over. People came out of their houses to find out whether anybody was in need of assistance. But the calm was only due to the fact that the centre of the cyclone was passing over the island" (Hazareesingh, 1948, p. 13)

The consequences of this misapprehension are not as clear (or deadly) as was the case for 1892, since "fortunately the loss of life was comparatively small" . Regardless, this suggests that for at least part of the Mauritian community, the memory of the cyclone eye had been lost since 1892 .

The next experience of a full eye calm came in 1960 with the destructive cyclone Carol that killed 42 people, the central eye of which took four hours to cross Mauritius on $28^{\text {th }}$ January $^{10}$. Once again, the archive data suggest that large proportions of the population believed the cyclone to be over, as exemplified in the following quote from a letter recounting the experience:

"The wind and the rain then gradually subsided, and the sun having made its appearance in the sky cast its shining beams upon on the earth which Carol had so severely struck ... many people were busy repairing their houses whilst others ... were loitering in the streets, looking at the sad spectacle which nature exhibited ... I learnt that the cyclone would soon revert upon us. ... q quickened my steps and broke the sad news to my family and my host. I had scarcely finished speaking when all of a sudden, the wind accompanied by large showers began to blow furiously. People running from all directions converged on our refuge." 11

\footnotetext{
${ }^{8}$ Le Cernéen / 1945 / $22^{\text {nd }}$ of February / NL

${ }^{9} \mathrm{NA} / \mathrm{SD} / \mathrm{337} / \mathrm{1945}$ / V1 / p3-4

${ }^{10}$ NA / Z-Cat / MMS / Annual report 1960; NA / B4 / A / 1960 / V1 / p5 - debates-governors' speech, 22 ${ }^{\text {nd }}$ of March

${ }^{11}$ Cloret, J / 1960 / My experiences during a cyclone - personal recollections written in 1960, see also NA / OHU / 1960 / No.31
} 
According to minutes of government debates, during the eye calm of Carol a number of police cars with loud hailers drove around certain areas in Mauritius on the instructions of the Royal Alfred Observatory (RAO) in order to warn people about its return ${ }^{12}$ :

\footnotetext{
"When the centre was passing over Mauritius and while the Police was out in Curepipe in cars ... telling the people to take all precautions because the cyclone was not over yet and that winds would blow more violently in the afternoon, everywhere hundreds of people went into the nearby forests and took away the timber which was lying there." 13
}

Interviews conducted for this study show that the eye of Carol is currently a well-established part of the collective memory of Mauritians. 19 interviewees recalled the cyclone eye; however, only seven stated that the police informed them the cyclone was returning, whist five stated that there was no warning the cyclone conditions would return. 13 interviewees attested that they left shelter during the eye of Carol supposing it had ended, and started clearing debris or similar, before it returned at full force.

The next experience of a full lull was cyclone Gervaise, which passed directly over Mauritius on $6^{\text {th }}$ February 1975. According to Padya (1976), the lull lasted four hours in most areas. Although widespread misinterpretation of the lull is not evident, several newspapers reported that communication about the passage of the eye was lacking:

"Why did police patrol cars not circulate during the lull to warn the population, deprived of radio and $T V$, that the danger was still real and to ask them to stay at home or to move to safer shelters?"14

This criticism of the warning communication was also reflected in the community interviews:

\footnotetext{
"At 9 or 10 am - they [the neighbours] had said it was ok - and that you can come out and move a little bit - after 30 mins or one hour, the cyclone came back very rigorously - it was terrible - it was the eye, close to Mauritius - it caused a lot of damage - they [Mauritius Meteorological Service] were not able to read properly the storm" (SSVC106)
}

Of the nine people who died during Gervaise, two are cited as due to venturing outside ${ }^{15} .109$ out of 139 interviewees conducted in 2019 mentioned or remembered Gervaise; yet, only eight interviewees mentioned experiencing a central calm.

\footnotetext{
${ }^{12}$ NA / B4 / A / 1960 / V2 / p935 - Cyclone Carol

13 Ibid.: 10 May - Mr Duval - Supplementary Estimates p936

${ }^{14}$ Week-End / $1975 / 11^{\text {th }}$ of February / NL

${ }^{15} L^{\prime}$ Express / 1975 / 11 $1^{\text {th }}$ of February / NL
} 
There was a comparatively brief interval before the next eye calm, when Cyclone Claudette passed over Mauritius between 01:30 and 05:00 on 23 ${ }^{\text {rd }}$ December 1979 (Padya, 1989, p. 163). The central calm associated with the passage of the eye was felt over a large portion of the island ${ }^{16}$. The conditions within the eye were described as hot and humid, providing a short period of respite, suffocating and humid conditions, with a diameter of about $21 \mathrm{~km}(13 \mathrm{~m})^{17}$. No archive source was found in which the passage of the eye was portrayed as unexpected, likely since Gervaise was only four years prior, so the experience of an eye would still been fresh. Only four interview participants who mentioned cyclone Claudette could recall the eye, of which only one acknowledged the calm (SSVC61), one said they thought the cyclone was over during the lull (SSVC138). Others suggested "there was no warning it was coming back" (SSVC142) or that "the radio told us not to go out so we stayed inside" (SSVC73).

The last eye calm was that of Cyclone Hollanda on $10^{\text {th }}$ February 1994. This cyclone did not directly cross Mauritius (as was first predicted), but instead skirted the island $20 \mathrm{~km}$ to the North West ${ }^{18}$. Therefore, there is almost no mention of an eye in the archive data, save from one report from residents of Grand Bay and Beau-Bassin (in the North East of the Island). Two interviewees claimed they experienced an eye calm during Hollanda, including one from the North East (Pointe aux Biches) which also provides timings approximately in line with Hollanda:

"Hollanda went away and came back, when it first came it was a little damage, but when it came back there was a surprising amount of damage, like trees you wouldn't expect to be brought down were felled ... Five o'clock it went and there was the sun, we went outside to pick up the fruits which fell down and then the weather became black and around 8, 8.30 it came back. Lots of screaming and wild noise" (SSVC81)

In 2002 cyclone Dina passed 50km to the north of Mauritius, and therefore there is no mention of a lull found anywhere in the archive data. Yet the response while Dina moved away from Mauritius also suggests that communities could have once again come outside as soon as possible and may not follow the official warnings, as was reported; "the villagers of the North come out with a hatchet, rake and axe to clear and rebuild at first light, while the maximum cyclone warning is still in effect"19 and "when the maximum alert was still in effect, the villages were already teeming with activity. The daylight attracted men, women and children outside in the streets. It was about seeing everything we heard in the dark during the night. "20

\footnotetext{
${ }^{16}$ NA / Z-Cat. / Technical Report - CS 5 -Cyclone season of the southwest Indian ocean 1979-1980 / p17

17 La Mauriciene / $1979 / 28^{\text {th }}$ of December / NL

18 L'Express / $1994 / 11^{\text {th }}$ of December / NL

19 L'Express / 2002 / 23rd January / NL

20 ibid.
} 


\section{Contemporary perceptions of the cyclone eye}

The community interviews included a number of questions about the experience of being in a cyclone eye, and the understanding of the characteristics of cyclones based on past memories, expectations and perceptions of risk. If this data from participants did not reflect awareness of the potential for a cyclone eye, then an additional question was posed around the framing if the sun comes out suddenly, and the wind stops, is it then safe to go outside?'. The majority of interviewees had responses that either directly mentioned the eye or suggested awareness of the central calm (such as needing to wait for an 'all clear' before going outside). Yet, 16 interviewees had responses which suggest they may have no awareness of cyclone eyes, for example:

"If the wind and rain go away and the sun comes out it means the cyclone has gone, now start cleaning" (SSVC47)

In addition, 22 participants did not mention the eye or the possibility for a lull. This included 18 interviewees who only described cyclones in the terms of a linear progression and decline of severity using the warning class system; that is after the warning reaches class four, any decline in the storm conditions may be interpreted as a result of the cyclone coming to an end. An additional ten responses included misunderstandings of cyclones, ranging from the potential physical characteristics, the warning stages, the mischaracterisation of the eye as a recurve, the duration of the calm and others. Both these groups were diverse, with a range of demographics, suggesting no particular pattern to those who remembered or forgot the cyclone eye. It is worth noting that secondary school education in Mauritius includes lessons on cyclones and their structure, and there have been several awarenessraising initiatives and publications ${ }^{21}$ that include details about past cyclones in the past. This might explain a certain level of complacency surrounding knowledge regarding cyclones. The data collected here certainly question the claim made in the Mauritius Times in 1994 that "every EVS student [secondary school] today knows ... the centre of the cyclone system"22.

\subsection{Seasonal timing}

While the current official cyclone season is categorised as running from $1^{\text {st }}$ November until $15^{\text {th }}$ May (NDRRMC, 2015), this has not always been the case. The perception that the seasonal timing of cyclones has changed is found as early as 1708 , in François Leguat's ${ }^{23}$ travelogue: "Hurricanes ...

\footnotetext{
${ }^{21}$ Including the booklets 'Cyclone Watch' (1994) a joint publication by MMS and the Ministry of Information and "let's talk about cyclones' (unknown year) by the government information service and prime minister's office

${ }^{22}$ Mauritius Times / 1994 / $18^{\text {th }}$ of February / NL

${ }^{23}$ French naturalist and explorer, for a time was a Protestant refugee on the then uninhabited Rodrigues Island before escaping to Mauritius
} 
formerly frequent, have become rare; when a hurricane arrives, it is never until February $9^{\text {th }}, 24$. Pridham (1849, p. 241), a historian and colonial chronicler, noted that "Hurricanes were constant in [February] till 1789: since then less frequent, but the inhabitants prepare for them, in case they should renew their periodical ravages". Storms that occur in January are "sometimes accompanied by thunder, though by no means violent, ... the tempestuous season now approaches" and that February is characterised by "violent gales of wind, perchance hurricanes and thunder". The risk was deemed to essentially be over by March, when the "torrents are now less strong and impetuous: rains less frequent" (Pridham 1849, p. 241). In 1852 the official Mauritius Almanac (published by the government) described the cyclone season as starting in December, when cyclones "pass near or over Mauritius, but they are not extensive, and do not cause much injury; they are dominated by bourrasques [squalls]" and ending in April, when "hurricanes are to be apprehended ... until the $18^{\text {th }, 25}$.

By the early 1890s, after over ten years without "having been visited by the slightest hurricane" the cyclone season was generally defined by the austral summer; that is, December until $\mathrm{March}^{26}$. The deadly 1892 cyclone, which stuck on $29^{\text {th }}$ April, is thus referred to as a surprise in almost all archive documents, and thus literally unpredictable. Many archive documents illustrate the surprise attributed specifically to the seasonal timing of the cyclone:

"I was dazed! How in the last days of April could a cyclone of such strength hit Mauritius! my conviction, until then, - the conviction of ignorance, alas! - was that past March, no meteor of this kind was to be feared. "27

"It was completely unexpected, for never has a hurricane been heard of so late in the year. From December 15 to April 15, cyclonic storms, unwelcome visitors at all times, have a prescriptive right to range these latitudes, but after the latter date is past-when our cold weather sets in - they are supposed to go into winter quarters. Who then ever dreamed of a cyclone approaching? ",28

Perhaps most importantly, Charles Meldrum, director of the RAO at the time stated:

"The reasons why it was considered that the force of the wind would not exceed that of a strong to a whole gale were that Mauritius had never been visited by a hurricane after the $12^{\text {th }}$ of April ... this cyclone has been unprecedented in Mauritius with regard to time of year. „29

\footnotetext{
${ }^{24}$ Leguat (1891) travelogue based on voyages between 1693 and 1698 / p9 / MG

${ }^{25}$ Mauritius Almanac, 1852 / p218 - Meteorological notes / NL

${ }^{26}$ Gazette des îles / 1892 / p18 / CPL - 1992 reprint

${ }^{27}$ Gazette des îles / 1892 / p35 / CPL - 1992 reprint

${ }^{28} \mathrm{NA} / \mathrm{B} 4 / \mathrm{A} / 1892$ / V2 / p14

${ }^{29} \mathrm{BB} / 1892$ / EE89 / NA
} 
Most of these statements are inconsistent with the archive record, with a "terrible" cyclone occurring as late as $2^{\text {nd }}$ May in 1702 and having severe impacts ${ }^{30}$. A gale lasting 24 hours also occurred in June $1785^{31}$, although this was not judged to be the full strength of a 'hurricane' (Walter, 1914). This was recalled after the 1892 cyclone, yet it was dismissed as somehow outside the relevant past; "but this is the $18^{\text {th }}$ century: old business!" and that before 1892 "Mauritius has thought herselfforever safe from a meteor of this kind"32.

Several archive sources directly attribute the catastrophic damages experienced in April 1892 to the belief that cyclones could not happen so late in the season:

"No hurricane appears to have produced so disastrous an effect because no hurricane ever came at so unexpected a moment, after the time generally set down for these visitations "33

As the governor at the time predicted, the 1892 cyclone did "modify many accepted principles of the ... laws of storms" $" 34$ and the date of the end of the cyclone season was moved to the end of April by sailors at the time ${ }^{35}$. This was further extended by mariners to run from $1^{\text {st }}$ November to the end of May after a number of early and late storms were tracked at sea during the 1911/1912 cyclone season ${ }^{36}$. This proved timely when a cyclone hit Mauritius between $26^{\text {th }}$ and $27^{\text {th }}$ May 1916 , uprooting trees and causing damage to the harbour at Port Louis (Chelin, 1973, p. 341; Padya, 1989, p. 161). Sources at the time lack the sense of shock at the seasonal timing, although it was far below the severity experienced in $1892^{37}$. The considerable impact of this cyclone on the late season sugar canes was recalled for a number of years, from $1931^{38}$ to 1960; "On the 26th of May! ... 1916... It was not, fortunately of the same violence as Carol or that of $1892^{\prime 39}$.

\footnotetext{
30 Pitot, A. / 1905 / T'Eylaudt Mauritius, Historical Sketches (1598-1710) / p354. It is interesting to note that this cyclone has not been entirely forgotten. It is noted in a 1989 textbook by a prior Mauritius Meteorological Service director Padya (1989, p. 157) as a "severe cyclone accompanied by torrential rain and widespread flooding. Plantations devastated; houses destroyed. It is reported that when the water receded from GRNW [Grand River North West] a large number of drowned stags were found suspended by their horns in the treetops".

${ }^{31}$ Determined to be under the threshold of a full hurricane (Walter 1914).

32 Gazette des îles / 1892 / p19 / CPL - 1992 reprint

${ }^{33}$ NA / SD / 152 / 1892 / V1 / p60

34 Jerningham / 1892 / p3 - Cyclone of April 29 - reprinted from Blackwood's Magazine, September 1892

35 Brebner, C.W. / 1912 / p18 - South Indian Ocean Cyclones of 1911 and 1912 / JPC

36 ibid.

37 Le Cernéen / 1916 / 29th of May / NL

${ }^{38} \mathrm{NL} / \mathrm{SD} / 351$ / 1931 / p258

${ }^{39}$ NA / B4A / 317 / 1960 / 08 / p4
} 
By 1927 the RAO had moved the end of the cyclone season back to $15^{\text {th }}$ May ${ }^{40}$. In 1931 , mentions of the seasonality of cyclones had started to slip into patterns common before 1892, with even official documents like the Mauritius Almanac stating that "cyclones are a frequent occurrence in the vicinity of Mauritius during the summer months from December to April ${ }^{\prime 41}$. Besides neglecting the possibility for early May cyclones, this suggests a potential conflation of 'to' April, with 'until' the start of April. A range of twenty-first century sources still incorrectly state the cyclone months; for example (from an online guide for tourists): "summer falls between the months of December and February.... Summer season is also cyclone season, but due to its location in the Indian Ocean, Mauritius is ideally located to miss the worst of it" (Hanief, 2018).

\section{Contemporary perceptions of the seasonal timing of cyclones}

As shown in Figure 2, the archive data collected for this research confirm that, from the earliest cyclone noted in the archive data in 1615, until the present, January and February do indeed have more cyclones in general. Yet, the risk of cyclones is also present from November until the end of May.

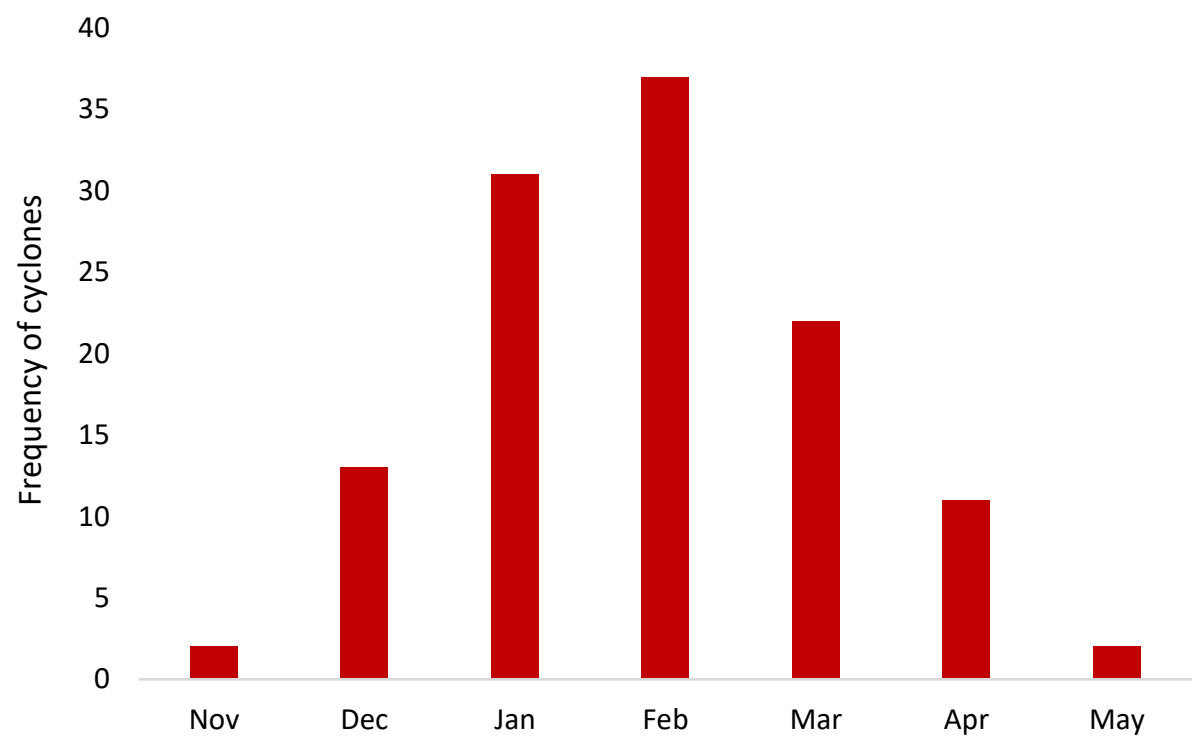

Figure 2: Cyclones by month effecting Mauritius from 1615 to present based on archive data

The lower frequency of cyclones in months like November, December, April and May has resulted in the tendency to emphasise the risk from cyclones during the so called 'major' cyclone months (colloquially January, February and sometimes March). Yet it also appears that over time this emphasis

\footnotetext{
${ }^{40}$ NA / Z-Cat / MMS / 1928 - misc. pub. No 7 - The cyclone season 1927-1928, Watson R.A.

${ }^{41}$ The Mauritius Alamac / 1932 / number 106 - 1931-32 / pE14 NL
} 
can result in the appreciation of cyclone risk in the less frequent months being reduced or even forgotten entirely, as is suggested by the material presented here.

In order to gauge current levels of perceptions, community interview participants were asked what months of the year cyclones could occur in Mauritius, and each month identified as a cyclone month was noted. A follow up question was asked to confirm that they had indeed listed all the months cyclones could happen (as opposed to only large ones or similar interpretations). These data are shown in Figure 3.

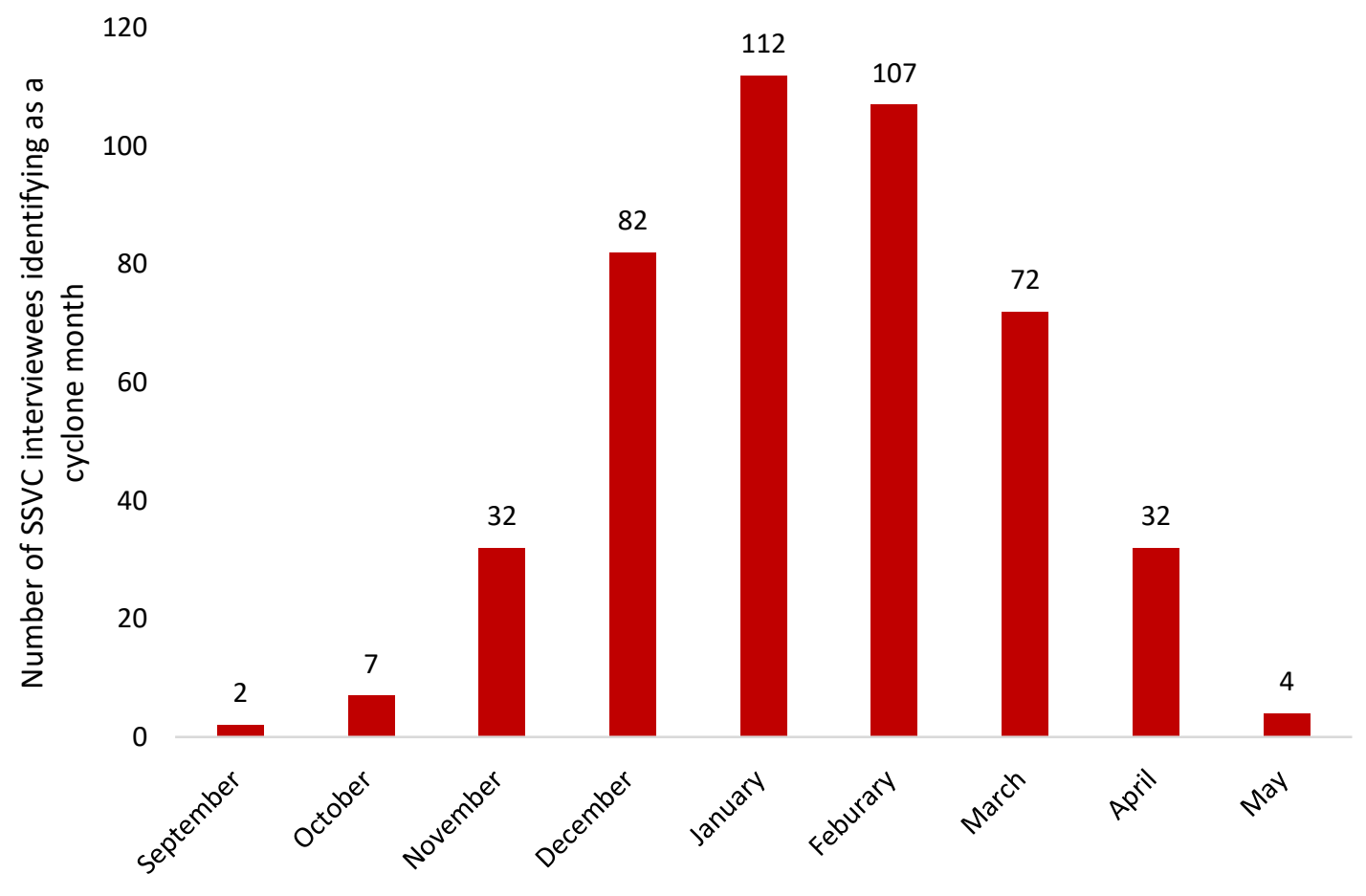

Figure 3: Perception of cyclone months by SSVC interview participants

While Figure 3 appears similar to the seasonal distribution of cyclones in the archive data shown in Figure 2, in fact these data shows that only 32 participants felt that cyclones could happen at all in Mauritius in either November or April, out of a total of 124 participants who specifically cited the months that cyclones could occur. Twelve responses also reflected a perception that the cyclone season had changed, for example:

"January and February, even December ... There might even be a cyclone in March, but it will never be big or dangerous. Not possible in April.... Because of climate change" (SSVC141).

These responses suggest that due to the lower frequency of cyclones in the less common months, like April or November, community members have forgotten the risk of cyclones in these months. Consequently, cyclones that do occur in these months in the future may be attributed as an impact of 
climate change, whereas in fact archive data suggest that cyclones have a history of occurring in these months and are just less frequent.

\subsection{Frequency and discourses of interval}

Meteorologists in Mauritius have consistently stated "there is no defined periodicity in cyclone formation $^{, 42}$. Yet there have been no shortage of attempts to assign a return period to cyclones by nonmeteorologists, from politicians to newspaper editorials. In many cases, these attempts occurred in the immediate aftermath of major cyclones, when the cyclones were discussed and analysed in order to make sense of the experience and provide reporting. In the early archive record the discussions of cyclone frequency were framed around the viability of the colony and warnings that "Mauritius is liable to periodical visits of this awful scourge" ${ }^{, 43}$, but there is little or no mention of past events as comparisons. Although the mention of past cyclones in relation to contemporary events became common through the nineteenth century, the concept of a 'normal' interval time between large cyclones only emerged consistently in the $20^{\text {th }}$ century as a product of a consecutive 15 -year interval period between many of the most damaging cyclones from 1931 until 1994. As a result this 15-year interval became received wisdom in Mauritius.

The earliest mention of a quiet period of around 15 years was found in relation to the period between the large cyclones of 1879 and 1892. This lull was ascribed by one commentator as a reason why the general public were unprepared for a severe cyclone "having remained more than fourteen years without having been visited by the slightest hurricane" 44 . A gap of 39 years then followed between the large cyclones of 1892 and 1931, during which there were multiple smaller cyclones, yet there is no mention found in any of the archive materials of this interval being perceived as normal or abnormal. In fact, as stated in the governmental debates "the cyclone of 1931 was not ... an unexpected event. Cyclones have visited this Colony from time immemorial"45. The discussions of a "normal' interval started to emerge following a number of large cyclones in 1945, particularly in government debates around the repayment of loans such as the following:

"How often do cyclones visit us? If every ten years, then the period [of repayment] should be ten years [Laughter]. If every thirty years we should provide for repayment in thirty years ... In 1931 [the] Government provided for repayment to be made over a period of thirty years. Now that we are again placed in similar circumstances we are still burdened with the loan of 1931. If we are to be visited by cyclones every fifteen years and are to reimburse loans over thirty years, then that way lies

\footnotetext{
42 Mauritius Times / 2018 / $18^{\text {th }}$ of January / OL - interview with M. Bodhoo

${ }^{43}$ Pridham, C. (1849) an historical, political and statistical account of Mauritius and its dependencies; p354 / CLC

${ }^{44} \mathrm{NA} / \mathrm{B} 4 / \mathrm{A} / \mathrm{1892} / \mathrm{V} 1 / \mathrm{p} 901$

${ }^{45}$ NA / B / 1935 / V1 / p358 - debates No.30 - 5 th Feb 1935 - regarding the 1931 cyclone
} 


$$
\text { bankruptcy,46 }
$$

It was indeed 15 years after 1945 that the next major cyclone, Alix, struck Mauritius in 1960, followed shortly by cyclone Carol. The governmental and newspaper archives include several references that demonstrate that this gap was long enough for the memory of cyclone risk to be eroded:

"After fifteen years of prosperity in this Island, we were living in a world of complacency and suddenly two cyclones came one on top of the other and shattered that complacency and we have come to realise suddenly that this Island is not free from the route of cyclones "47

This supposition was immediately used to minimise concerns of cyclone risk:

"The fact of our experience is that once we have had one cyclone or a series of cyclones in a year we are left free from their visitations for a period of some 12 or 15 years, 48

Much of the cautiousness in the use of the 15-year cycle concept ended when the next major cyclone, Gervaise, occurred exactly 15 years later in 1975. Newspaper headlines reported that "The 15-year fateful cycle (1931-1945-1960-1975) seems to be confirmed"49, despite a warning by the director of the Mauritius Meteorological Services (MMS) that "there is no evidence that there is such a cycle" The extrapolation that there would not be a cyclone for another 15 years was repeated with yet more confidence "Gervaise and her sisters will not be invited to pass, we expect, for at least a decade and a half ${ }^{, 51}$. This was even cited by a journalist in the closing remarks of an interview with the MMS director "the lesson is learned and will be used in the next cyclone in fifteen years" ${ }^{\text {, }}$, seemingly lending institutional credibility to the cycle, although the statement was produced by the journalist rather than the director.

Cyclone Claudette during the 1979/80 season was the next major cyclone, yet it was not as severe as Gervaise. When the following major cyclone, Hollanda, arrived in 1994, most comparisons and statements to the 'last cyclone' measure 19 years back to Gervaise, and not Claudette:

\footnotetext{
${ }^{46}$ NA/ B4 / 1945 / V5 / p1554 - debates (No. 120)

47 Ibid.: p355 - debates on the address, see also Le Mauricien / 1960 / $23^{\text {rd }}$ of January / NL and NA / B4 / A / 1960 / V1 / p5

- Governors speech

48 Ibid.: p79 - Mr V Govinden debates on the address

49 Le Cernéen / $1975 / 10^{\text {th }}$ of February / NL

50 L'Express / 1975 / $11^{\text {th }}$ of February / NL

$51 L^{\prime}$ Express / $1975 / 12^{\text {th }}$ of February / NL

52 ibid.
} 
"After 19 years we have suddenly fallen victim to a catastrophe. God forbid we are struck by another violent cyclone! It will then be the end of our prosperity ",53

In the wake of Hollanda several newspaper articles suggest that as a result of the interval people had once again (as in 1892, 1945, and 1960) started to forget their exposure:

"Mauritians have lost the cyclonic tradition because we have not had a cyclone in a long time. Hollanda took Mauritius by surprise .... Hollanda has revealed the weaknesses and deficiencies that have existed in Mauritius since Gervaise's passage „54

"Much has been said since the passage of Hollanda ... about the lack of cyclonic memory of Mauritians and their exaggerated belief in the famous 15 -year cycle, 55

This prompted one commentator, Dhookll, to write an article in the newspaper L'Express regarding 'Cyclonic Probabilities', which surmised that since Mauritius had "been severely hit by cyclones in 1931, 1945, 1960, 1975 and now in 1994, it is perhaps fairly accurate to assume that we can expect a bad cyclone about once every 15 years $"$ "56. The article went on to calculate the probability of being hit by a cyclone in any given year (calculating that it is 1/225) based on the pattern from 1931 onwards, that in 15 years "only one [cyclone] can be considered to constitute a real threat to Mauritius" "57. In addition to neglecting the combined impacts of less intense cyclones - and years such as 1945 and 1960 where two cyclones happened in the same year - this further enshrined the 15-year cycle.

The latest of the major cyclones to affect Mauritius, coming eight years after Hollanda, was Dina in 2002, although many of the community members interviewed in Mauritius identified Hollanda in 1994 as the last 'real' cyclone.

"people had the impression that cyclones come every 15 years ... the last cyclone, which is worth mentioning was in 1994" (SSVC96)

Regardless of the fact that the interval between Dina and Hollanda was eight years, the 15-year cycle once again surfaced in the media at the time:

\footnotetext{
53 Mauritius Times / 1994 / 24 $4^{\text {th }}$ of February / NL

${ }^{54} L^{\prime}$ Express / $1994 / 11^{\text {th }}$ of February / NL

55 Ibid.: $20^{\text {th }}$ of February

56 ibid.

57 ibid.
} 
"Cyclones are tied up with the fate of our island home ... they are in popular imaginations known or thought to hit the country every fifteen years ",58

\section{Contemporary perceptions on cyclone frequency}

Interviews conducted for this project included asking participants the number of years between 'large' cyclones affecting Mauritius. Of 135 responses, 102 included a judgement on the frequency of cyclones, plotted in figure 4. All answers that included a range of years (for example stating that cyclones occur every 7 to 10 years) were plotted as the lowest value in the range (i.e. as 7).

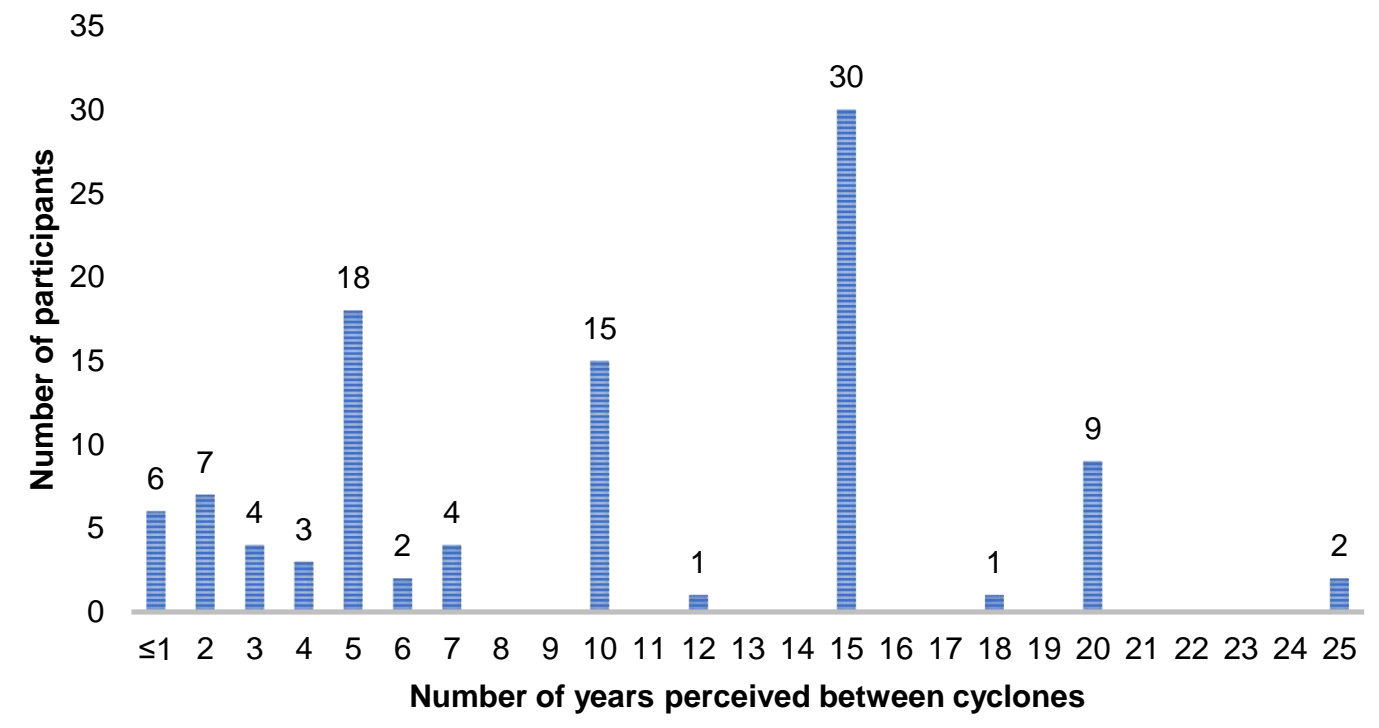

Figure 4: Number of perceived years between cyclones from SSVC interviews

While the 15-year return period is the largest single response $(n=30)$, there was also a range of other replies and a total of 59 participants (i.e. $58 \%$ of the participants who ascribed a numerical value to the return period) claimed that the return period is 10 years or less. This included six participants stating that one or more large cyclone happens in Mauritius every year, suggesting that certain people (perhaps those that have not witnessed a large cyclone) are defining cyclones by the experience of more recent and less severe events. Thus, considering the phrasing of the question, it would seem that some people consider medium or low severity cyclones (for example Berguitta in 2018) as being typified as a large cyclone. Consequently the perception of frequency shifts upwards and risk shifts downwards, since these less severe events are indeed more frequent. A further 30 participants said they did not know. Only nine participants did not feel there was a 'normal' interval and thus did not provide an estimation of interval.

\footnotetext{
${ }^{58}$ Mauritius Times / 2002 / 31 1 st of January / NL
} 
The interview data also show a considerable number of participants have determined that cyclones are no longer a threat, partly because the supposed pattern of 15 years is broken, and such an event has not happened in a comparatively long time. This has many parallels with the similar statements after long cyclone free periods in the archive. Of the 135 responses to the frequency question, 19 participants said that the frequency of cyclones had changed, and 23 specifically claimed that Mauritius now gets hit by less cyclones:

"Before it was every 15 years ... now it's just not many cyclones at all" (SSVC25).

"I think cyclones are getting less ... we used to get a lot of cyclones... [for] 7 to 8 years now we haven't had a good cyclone. I don't think we will ever again get a big cyclone like the past”'(SSVC49).

The interviews also collected perceptions of change in the frequency and strength of cyclones. Eleven interviewees claimed that cyclones had got worse (either in terms of intensity or damages), 14 responded that there had been no change, six said they did not know or were unsure. 72 participants expressed that cyclones are now less than in the past (either in strength or frequency). Of these, 28 also said that they believed that Mauritius would no longer be hit or affected by large cyclones ever again:

"Now there are less - and less strong - a cyclone like Carol could not happen again" (SSVC28).

Many of these responses were at least partly informed by the belief that climate change is an influence:

"We have noticed climate change here; summer is very hot, and winter is very cold. That's due to climate change, and its why we will not have the same kind of cyclones like we used to have" (SSVC16).

The interviews also revealed a prevalent discourse in Mauritius about the island's development level protecting it from cyclones. 69 community interviewees (out of 135 responses, i.e. $51 \%$ ) across 89 references (mostly in response to the question 'how at risk do you feel from cyclones?') suggested that Mauritius is now resilient in regard to the impacts of cyclones. Many of these comments specifically cited the shift in building materials, with 33 interviewees mentioning the conversion to building in concrete (often in relation to post 1960 cyclone Carol reconstruction):

"Now it is ok-everything is safe now compared to before - if a big one happens now it will be no impact" (SSVC56).

Several others also credit the perceived safety and resilience to the development of technology and forecasting: 
"If a cyclone like Carol happened now I don't think there would be much damage, we were wrongly equipped before, now we are well informed and well equipped ... I don't think it's going to be that damaging", (SSVC78).

These three interconnected processes (certain people defining what typifies as a large cyclones by the more frequent but less severe events; the supposed 15-year cycle broken; perceived resilient development) all contribute to one of the clearest trends from the interview data: that a considerable number of people in Mauritius seem to think that cyclones are either no longer a threat, no longer occur at all or have become significantly weaker. One of the consequences of this is that certain members of the community may ignore warnings:

"[We] get ... too many warnings. Now you get informed when its forming, it disintegrates, and you are informed day by day, on the radio and TV, they show you the graphs ... you don't take much notice because now there are practically no cyclones - maybe we should be careful, but we just don't care when they say it's coming ... in these last few years perhaps we have become a bit careless" (SSVC115).

The prioritisation of recent events in the memory of hazards is also demonstrated by a preoccupation with tsunamis. Of 21 participants who mentioned tsunamis during the interviews, nine expressed that they were a greater risk than cyclones and four thought tsunamis were an equal threat, despite Mauritius never having had a documented deadly tsunami in its occupied history. This often mapped onto the belief that Mauritius does not get large cyclones anymore:

'I don't feel at risk [from cyclones] - I'm quite safe - I don't think a cyclone like Carol could happen again - now there is tsunami, of course I am more scared of tsunami-whenever I hear the news, I am scared of it. When danger comes how would you know" (SSVC101)

This suggests that communities prioritise recent events (such as the 2004 tsunami, which was big news despite its lack of impact in Mauritius) and as a result may be either not taking precautions or actively pursuing activities which increase vulnerability, as was the case for many of the big cyclones in the past. One striking example is that 26 interview participants claimed cyclones are enjoyable, including 12 who mentioned that people go down to the beach to watch the sea. Only three interviewees confessed to doing this personally, for example a 22 -year-old participant stated:

“[When] there is a cyclone, I walk around, like its nothing - it's only rainfall and wind ... we even visit beaches, it's really cool - we go to watch the waves ... even some people go for a swim - and the government tries to ban that ... we really like it and welcome when there is a cyclone" (SSVC42) 


\section{Discussion}

The combined archive and interview data reveal that perceptions of what a cyclone is have changed considerably over time in Mauritius, either in terms of the experience of a cyclone eye, the seasonal timing, or the frequency of cyclones. These parallel and interconnected perceptions act out over the long term in repetitive patterns that are informed by memory, or more often forgetting. In the longer intervals between large cyclones and direct hits, Mauritians have repeatedly forgotten that cyclones can have a central calm, can occur in the lower frequency months such as April, or that they can occur at all.

These results suggest that such patterns of memory may be theoretically mapped onto the geometry of a helix. While the memory of cyclones and their characteristics has been repeatedly lost in Mauritius in the long periods between large cyclones, the experience of cyclones and the levels or form of memory do not return to the same point (nor could they). This is one of the central justifications for the helix conceptualisation, since portrayal as a cycle would be inaccurate. A helical concept, with its threedimensionality, allows for partially repetitive patterns to be highlighted without presenting a false return to an original state. In addition, not all helices act out uniformly in a perfect spiral. Instead, these can be represented as uneven, non-repetitive and unstable, and therefore this concept could account for the irregular distribution and impact of cyclones.

These patterns have played an influential role in how cyclones are experienced and responded to across Mauritian history. The extent of memory of past cyclones is therefore likely to be a critical factor in how people in Mauritius will respond to cyclones in the future. Thus, as for other repetitive environmental hazards, the impact and response to any single disaster has been heavily conditioned by the progression and sequence of past events - not just a sequela of the most recent comparable event within which memory plays a complex role (Endfield et al., 2004). Equally, and as detailed by Monteil et al. (2020), accounting for forgetting disasters can help explain the "reproduction of drivers of vulnerability despite a recent experience of disaster". Consequently, understanding this memory and its patterns are of key importance to DRR.

One necessary observation when examining patterns of disaster memory is the disconnect between severity as a hazard parameter, and hazard impact or experience. Just as foundational vulnerability literature asserts that the physical strength of a natural hazard (such as that derived from instrumental data) is not proportionately related to impact (which is determined by vulnerability: Lewis, 1979; Hewitt, 1983), the extent to which cyclones are remembered is also not proportionately related to severity by hazard parameter. This is shown in the multiple statements that Hollanda was the last 'real' cyclone, despite the fact that Dina had higher recorded windspeeds (MMS, 2016). Equally, in 1994 
after cyclone Hollanda, most comparative statements looked back at Gervaise (1975) and not Claudette (1979). Yet the difference between Gervaise and Claudette in terms of instrumental measurements was not great; Claudette brought gusts of $220 \mathrm{~km} \mathrm{~h}^{-1}$, killed six people and destroyed or damaged over 3000 buildings, while Gervaise brought gusts of around $210 \mathrm{~km} \mathrm{~h}^{-1}$ (with a single very high reading of $280 \mathrm{~km}$ $\mathrm{h}^{-1}$ in one location), killed nine people and destroyed over 3000 houses. Indeed, at the time Claudette was described by the governor as "one of the most violent cyclones ... an intensity close to that of Gervaise" ${ }^{, 59}$.

The widespread identification of Gervaise as the last 'real' cyclone before Hollanda can only be explained by examining severity of experience. The levels of memory of each event cannot be solely explained by windspeed or any single hazard severity parameter. Gervaise was likely more traumatic and thus memorable due to the longer period of cyclone-free years before the cyclone and the erosion of memory of more distant prior experiences. Thus, forgetting in one sense is a precondition of memory, which supports the conceptualisation of memory as acting out in helices and the neither linear nor circular evolution based on both past events and improvisation (Bankoff, 2009; p. 277). Equally the forgetting of Claudette was aided by the fact that it did not fit into the neat 15 -year pattern that was already well established in popular imagination at this point. As Aviles (2015) argues, it is the 'popular' cyclones which become inscribed into memory, refuting the assumption that cyclones are proportionately remembered according to strength (although this use of 'popular' risks circular reasoning). The results also suggest a preoccupation with recent events and the present or 'tempophilia' (Kelman et al., 2017) regarding memory of hazards demonstrated by the current preoccupation with tsunamis. Thus, experiences and perspectives both forgotten and remembered, past and present, should be included as a focus of disaster research and not just narrow physical measurements of severity.

These results also suggest that the designation of events as 'unprecedented' is highly dependent on memory. As Hewitt (1983) argues, 'unprecedented' is part of a lexicon that builds a discourse of discontinuity regarding disasters and works to detach disasters from the rest of human-environment relations and social life. Even the identification of so-called unprecedented events encourages an ahistorical view and the concept of a discrete unit in space and time. Such a differentiation also depends on the depth of memory and cultural specifics, since the extent to which cyclones are seen as a surprise and their rationalisation varies widely. What one Mauritian considers an unprecedented and unexpected cyclone, another may view as routine or within a pattern as informed by historical understanding. This suggests that the concept of, and differentiation between, Grey or Black Swan ${ }^{60}$ cyclones (see Lin and

\footnotetext{
${ }^{59}$ NA / BA / 1975 / V1 / p6 - speech from the throne - governor general

60 A 'Black Swan' is used to describe a high impact event that is unanticipated and unpredicted, while grey swans are similarly high consequence events that are also supposedly unobserved and unanticipated but which can ultimately be predicted, foreseen and prepared for. (Lin and Emanuel, 2016)
} 
Emanuel, 2016) may be a red herring (Shaw, 2014). Particularly since the differentiation revolves around the designation of a storm as 'unprecedented', reinforcing the need to pay attention to the role of memory in determining the different scales at which 'extreme' vs 'routine' is decided and for whom (Krüger et al., 2015). Furthermore it is equally important to examine what has been forgotten as well as what is remembered, since even if the memory of the past is now totally defunct, research should aim to contextualise the past and current memory and knowledge to see if any lessons can be learned to understand contemporary vulnerability (García-Acosta, 2017, p. 18).

This case study underscores that memory is a component of both vulnerability and resilience which are both long term processes, not fixed or static states to be attained (Lewis, 1979; Oliver-Smith and Hoffman, 1999). In highlighting the historical and human influences that are uncovered by investigating the role of memory and forgetting in the creation of vulnerability and responses to tropical cyclones across Mauritian history, this research also rejects the concept of a 'natural' disaster, in line with literature established as early as the 1970's (Ball, 1979; Dynes, 1975; O'Keefe et al., 1976; White, 1974).

The repetition of certain experiences of cyclones in Mauritius also demonstrate that memories are a palimpsest; that they are rewritten and reshaped retrospectively, as particularly shown in the adoption of the 15-year cycle concept and the marginalisation of events in the past that do not fit the pattern. This can be accounted for in the helical conceptualisation of patterns, since a helix is also a continuous function which allows for the constantly occurring processes of creating, modifying and eroding memory, in contrast to portrayals of memory of disasters in the past only being created at the moment of the event itself. This feeds into the well-established concept that cyclones (and all disasters) are 'made' as much as they are experienced, and are social texts as much as material occurrences that are culturally interpreted and conceptualised (Endfield et al., 2009; Oliver-Smith and Hoffman, 1999). This process of event making does not end with the post disaster recovery, and as Morgan (2017) argues, climatic extremes and disasters can be culturally recast long after their impacts have ended and far from their original experience.

This research has demonstrated a wide diversity of perspectives and different memories of cyclone experiences across time in Mauritius. Beyond older participants having a longer memory, these differences do not appear to depend on the socio-demographic characteristics of those sampled, although more investigation is needed since gender and cultural social-demographics (among others) are likely to influence the distribution and form of memories (Herlitz et al., 1997). Therefore, further research is required into the scales of memory construction among society and indeed these scales 
should be considered in any examination of disaster memory. The multi-scalar nature of a helical conceptualisation of the operation of memory and disaster response allows for this since a helix can exist at any scale.

This research has a number of implications in the context of the recent increase in attention on 'cascading disasters' (see Pescaroli and Alexander, 2015; p59). Cascading disasters can be defined as "extreme events, in which cascading effects increase in progression over time and generate unexpected secondary events of strong impact". While attention on the temporal and interconnected nature of disaster is shown to be essential by this research, the results also urge caution in the use of a single hazard being a 'start' point, and instead that many of the historical long-term processes (including those involving memory) existed before the hazard manifested (and as argued in baseline disaster literature Alexander, 1993; Hewitt, 1983; Blaikie et al., 1994); thus disasters have multiple causes, including the memory of previous disasters (or lack of). The delineation between the causes and effects, including their various loops and overlaps cannot be precisely indicated as suggested by the definition of cascading disasters. This is another justification of the conceptual mapping of the responses and memory of cyclones in Mauritius onto a helix. The start and finish are not necessarily definable, since cyclone disasters in Mauritius are processes (Hewitt, 2014; Lewis, 1999; Wisner et al., 2004), acceding to the suggestion that all disasters are in fact slow disasters by nature (Lewis, 1988; Perry and Quarantelli, 2005).

\section{Conclusions}

This research has uncovered that memory, or more specifically forgetting, has played a considerable role in the experience and impact of cyclones in Mauritius. A pattern of repetitive forgetting is apparent regarding when cyclones can occur, how often they happen and the very possibility of a central calm. These patterns are shown to be occurring today.

As Schenk (2015, p. 77) notes, the utility and existence of memory of past disasters is often assumed, and that "exploration of disasters from the past indicates that societies have mainly learned from disasters when disasters have been a recurrent phenomenon". Yet, this research demonstrates the experience of and repetitive processes behind forgetting of a collective and long-term nature appears to play a central role in the impact of, and response to tropical cyclones in Mauritius. This invokes George Santayana's (1905) celebrated dictum "those who cannot remember the past are condemned to repeat $i t^{\prime \prime}$.

This research therefore suggests that in order to design and implement effective DRR in Mauritius and elsewhere, the long-term processes involved in the creation and perpetuation of vulnerability must first 
be understood, one key element of which is the role of memory. In order to achieve this, an examination of disaster history and the longue durée is needed, and particularly one that places an examination of memory at its centre, in order to account for the complex, obscured, slowly changing structural influences of vulnerability that extend into the distance in time and space. Conceptualising these patterns as helical in shape and nature may assist in these efforts.

It is inevitable that a large cyclone will eventually strike Mauritius. It may be in the distant future, or it may be next cyclone season (the dates of which vary depending on who you speak to). When the next cyclone does strike, the way it is experienced and responded to will be heavily conditioned by memory and forgetting. These results thus highlight the potential of a longue durée approach and methods to uncover historical influences on vulnerability and the 'structural knowledge' behind disasters (Schenk, 2007). Investigations of the longue durée can uncover these vulnerabilities and while historical research combined with social science is time consuming, difficult and inherently place based, without considering the experiences of the past they are likely to be repeated, potentially with deadly consequences.

\section{References}

Adamson, G.C.. (2012), "'The languor of the hot weather': everyday perspectives on weather and climate in colonial Bombay, 1819-1828", Journal of Historical Geography, Vol. 38 No. 2, pp. 143-154.

Adamson, G.C.D., Hannaford, M.J. and Rohland, E.J. (2018), "Re-thinking the present: The role of a historical focus in climate change adaptation research", Global Environmental Change, Vol. 48 No. January, pp. 195-205.

Alexander, D. (1993), Natural Disasters, Routledge, London, available at: https://www.taylorfrancis.com/books/9781351429238 (accessed 27 August 2019).

Aviles, B. (2015), "Taken By Storm 1938: A Social and Meteorological History of the Great New England Hurricane. By Lourdes B. Aviles.", Environmental History, Vol. 20 No. 3, pp. 562-564.

Ball, N. (1979), "Some Notes on Defining Disaster: Suggestions for a Disaster Continuum", Disasters, Wiley/Blackwell (10.1111), Vol. 3 No. 1, pp. 3-7.

Bankoff, G. (2004), "Time is of the Essence: Disasters, Vulnerability and History", International Journal of Mass Emergencies and Disasters, Vol. 22 No. 3, pp. 23-42.

Bankoff, G. (2007), "Comparing vulnerabilities: Toward charting an historical trajectory of disasters", Historical Social Research, Vol. 32 No. 3, pp. 103-114.

Bankoff, G. (2009), "Cultures of Disaster, Cultures of Coping", in Mauch, C. and Pfister, C. (Eds.), Natural Disasters, Cultural Responses: Case Studies toward a Global Environmental History, Lexington Books., New York.

Bankoff, G., Cannon, T., Kruger, J. and Schipper, E.L.F. (2015), "Exploring the links between cultures and disasters", in Kruger, F., Bankoff, G., Cannon, T., Orlowski, B. and Schipper, E.L. (Eds.), Cultures and Disasters, 1st ed., Routledge, New York, pp. 1-16.

Barclay, J., Wilkinson, E., White, C.S., Shelton, C., Forster, J., Few, R., Lorenzoni, I., et al. (2019), "Historical Trajectories of Disaster Risk in Dominica", International Journal of Disaster Risk Science, Vol. 10 No. 2, pp. 149-165.

Blaikie, P., Cannon, T., Davis, I. and Wisner, B. (1994), At Risk. Natural People's Vulnerability and Disasters, Routeledge, London, available at: 
https://www.taylorfrancis.com/books/9781134528615 (accessed 24 September 2018). Bosher, L. (2005), "The Divine Hierarchy": The Social and Institutional Elements of Vulnerability in South India., Loughborough, available at: https://hdl.handle.net/2134/9896.

Cannon, T. (2013), "Community Based Adaptation: Current Observations", Community Based Adaptation Conference Seven, International Institute of Environment and Development, Dharka Bangladesh.

Chelin, A. (1973), Maurice : Une Île et Son Passé, 1st ed., Collection : Bibliothèque indianocéanienne, Port Louis, available at: https://gallica.bnf.fr/ark:/12148/bpt6k3340063x.textelmage (accessed 26 June 2019).

Chenoweth, M. (2006), "A Reassessment of Historical Atlantic Basin Tropical Cyclone Activity, 17001855", Climatic Change, Vol. 76 No. 1-2, pp. 169-240.

Chenoweth, M. (2014), "A new compilation of North Atlantic tropical cyclones, 1851-98", Journal of Climate, Vol. 27 No. 23, pp. 8674-8685.

Daniel, C., Maharaj, R. and De Souza, G. (1986), "Tropical Cyclones Affecting Trinidad and Tobago, 1725-2000", Meteorological Service of Trinidad and Tobago, p. 14.

Dynes, R. (1975), "The comparative study of disaster: A social organizational approach", Mass Emergencies, Vol. 1 No. 1, pp. 21-31.

Endfield, G., Davies, S., Tejedo, I.F., Metcalfe, S.E. and O'Hara, S.L. (2009), “Documenting disaster: archival investigations of climate, crisis and catastrophe in colonial Mexico", in Mauch, C. and Pfister, C. (Eds.), Natural Disasters, Cultural Responses: Case Studies toward a Global Environmental History, Lexington Books., New York.

Endfield, G.H. (2007), "Archival explorations of climate variability and social vulnerability in colonial Mexico", Climatic Change, Vol. 83 No. 1-2, pp. 9-38.

Endfield, G.H. (2012), "The resilience and adaptive capacity of social-environmental systems in colonial Mexico", Proceedings of the National Academy of Sciences, Vol. 109 No. 10, pp. 36763681.

Endfield, G.H., Tejedo, I.F. and O'Hara, S.L. (2004), “Drought and disputes, deluge and dearth: climatic variability and human response in colonial Oaxaca, Mexico", Journal of Historical Geography, Vol. 30 No. 2, pp. 249-276.

Endfield, G.H. and Veale, L. (2017), "Climate, culture and weather", Cultural Histories, Memories and Extreme Weather, Routledge, pp. 1-15.

Fazey, I., Pettorelli, N., Kenter, J., Wagatora, D. and Schuett, D. (2011), "Maladaptive trajectories of change in Makira, Solomon Islands", Global Environmental Change, Vol. 21 No. 4, pp. 12751289.

Garcia-Acosta, V. (2007), "Risks and Disasters in the History of the Mexico Basin: Are they Climatic or Social?", The Medieval History Journal, Vol. 10 No. 1-2, pp. 127-142.

García-Acosta, V. (2017), "Building on the past: Disaster Risk Reduction including Climate Change Adaptation in the Longue Durée", in Kelman, I., Mercer, K. and Gaillard, J. (Eds.), The Routledge Handbook of Disaster Risk Reduction Including Climate Change Adaptation, Routledge, Abingdon, pp. 203-213.

García-Hernández, C., Ruiz-Fernández, J. and González-Díaz, B. (2019), "Inherited memory, social learning, and resilience: lessons from Spain's Great Blizzard of 1888", Geographical Research, Blackwell Publishing Ltd, Vol. 57 No. 2, pp. 189-203.

Garde-Hansen, J., Mcewen, L., Holmes, A. and Jones, O. (2017), "Sustainable flood memory: Remembering as resilience", Memory Studies, Vol. 10 No. 4, pp. 384-405.

Garnier, E. and Desarthe, J. (2013), "Cyclones and Societies in the Mascarene Islands 17th-20th Centuries", American Journal of Climate Change, Vol. 02 No. 01, pp. 1-13.

Glantz, M.H. (1988), An Essay on the Interactions Between Climate and Society, CO: National Center for Atmospheric Research.

Glantz, M.H. (2003), Climate Affairs: A Primer, Island Press, Washington, available at: https://books.google.co.uk/books?hl=en\&lr=\&id=YqGc2yE9blwC\&oi=fnd\&pg=PR13\&dq=Glantz 
,+M.H.+2003a+Climate+Affairs:+A+Primer.+Covelo,+California:+lsland+Press\&ots=upezGuU9rw \&sig=8_-XiZSx-rr3roS5G2GciDQjgSc (accessed 26 January 2016).

Golinski, J. (2007), British Weather and the Climate of Enlightenment, University of Chicago Press, available at:

https://books.google.co.uk/books?hl=en\&lr=\&id=KP5AP2POGOUC\&oi=fnd\&pg=PR7\&dq=britis $\mathrm{h}+$ weather+and+the+climate+of+enlightenment\&ots=ElmFW5ZHyE\&sig=a5eCWrzie2IYWuxCB9 F3EYQINAg\#v=onepage \&q=british weather and the climate of enlightenment\& $f=f a l s e$ (accessed 12 September 2018).

Hall, A. and Endfield, G. (2016), "'Snow Scenes': Exploring the Role of Memory and Place in Commemorating Extreme Winters", Weather, Climate, and Society, Vol. 8 No. 1, pp. 5-19.

Hanief, Z. (2018), "Climate of Mauritius and best time to visit", TravelStart, available at: http://www.travelstart.co.za/blog/best-time-to-visit-mauritius/\#ixzz5nqNWAwCT (accessed 14 May 2019).

Hazareesingh, K. (1948), The Story of the 1945 Cyclones, Govt. Printer, Port Louis, available at: https://catalogue.nla.gov.au/Record/927594 (accessed 17 September 2019).

Herlitz, A., Nilsson, L.G. and Bäckman, L. (1997), "Gender differences in episodic memory", Memory and Cognition, Springer New York LLC, Vol. 25 No. 6, pp. 801-811.

Hewitt, K. (1983), "The idea of calamity in a technocratic age.", in Hewitt, K. (Ed.), Interpretations of Calamity, The risks., Allen and Unwin, Boston, pp. 3-32.

Hewitt, K. (2014), Regions of Risk, Regions of Risk, Routledge, London, available at:https://doi.org/10.4324/9781315844206.

Hicks, A. and Few, R. (2015), "Trajectories of social vulnerability during the Soufrière Hills volcanic crisis", Journal of Applied Volcanology, Vol. 4 No. 1, p. 10.

Hills, A. (1998), "Seduced by recovery: The consequences of misunderstanding disaster", Journal of Contingencies and Crisis Management, Vol. 6 No. 3, pp. 162-170.

Hoelscher, S. and Alderman, D.H. (2004), "Memory and place: Geographies of a critical relationship", Social and Cultural Geography, Taylor and Francis Ltd, Vol. 5 No. 3, pp. 347-356.

Janković, V. and Fleming, J.R. (2017), "Post-scripting extreme weather", Cultural Histories, Memories and Extreme Weather, Routledge, New York, pp. 154-165.

Jones, C.A., Davies, S.J. and Macdonald, N. (2012), "Examining the social consequences of extreme weather: The outcomes of the 1946/1947 winter in upland Wales, UK", Climatic Change, Springer Netherlands, Vol. 113 No. 1, pp. 35-53.

Kelman, I., Upadhyay, H., Simonelli, A.C., Arnall, A., Mohan, D., Lingaraj, G.J., Nair, S., et al. (2017), "Here and now: perceptions of Indian Ocean islanders on the climate change and migration nexus", available at:https://doi.org/10.1080/04353684.2017.1353888.

Krüger, F., Bankoff, G., Cannon, T., Orlowski, B. and Schipper, E.L.F. (2015), Cultures and Disasters: Understanding Cultural Framings in Disaster Risk Reduction, 1st ed., Routledge, London.

Lewis, J. (1979), "The vulnerable state: An alternative view", in Stephens, L.H. and Green, S.J. (Eds.), Disaster Assistance: Appraisal, Reform and New Approaches, New York University Press, New York, pp. 104-129.

Lewis, J. (1988), "On the line: An open letter in response to 'Confronting natural disasters, an International Decade for Natural Hazard Reduction", Natural Hazards Observer, Vol. XII No. 4, p. 4.

Lewis, J. (1999), Development in Disaster Prone Places: Studies of Vulnerability, ITDG Publishing, London, available at: http://library.wur.nl/WebQuery/clc/980719 (accessed 7 June 2016).

Lewis, J. (2015), "Cultures and Contra-cultures: Social devisions and behavioural origins of vulnerabilities to disaster risk", in Kruger, F., Bankoff, G., Cannon, T., Orlowski, B. and Schipper, L. (Eds.), Cultures and Disasters, 1st ed., Routledge, New York, pp. 109-154.

Lin, N. and Emanuel, K. (2016), "Grey swan tropical cyclones", Nature Climate Change, Vol. 6 No. 1, pp. 106-111.

Lorenzoni, I. and Pidgeon, N.F. (2006), "Public views on climate change: European and USA 
perspectives", Climatic Change, Vol. 77 No. 1-2, pp. 73-95.

Mahony, M. (2018), "The 'genie of the storm': cyclonic reasoning and the spaces of weather observation in the southern indian ocean, 1851-1925", British Journal for the History of Science, British Society for the History of Science, Vol. 51 No. 4, pp. 607-633.

Manyena, S.B. (2012), "Disaster and Development Paradigms: Too Close for Comfort?", Development Policy Review, Vol. 30 No. 3, pp. 327-345.

Mauritius Meterological Service. (2016), "Cyclone Warning System - General information", MMS, available at: http://metservice.intnet.mu/tropical-cyclone/warning-system.php (accessed 16 October 2018).

McKinnon, S. (2019), "Remembering and forgetting 1974: the 2011 Brisbane floods and memories of an earlier disaster", Geographical Research, Vol. 57 No. 2, pp. 204-214.

McKinnon, S. and Cook, M. (2020), "Five days of swirling fury: Emotion and memory in newspaper anniversary reports of the 1974 Queensland floods", Emotion, Space and Society, Elsevier, Vol. 35 No. October 2019, p. 100685.

Mock, C.. (2004), "Tropical Cyclone reconstructions from documentary records: examples from South Carolina", in Murname, R. and Liu, K. (Eds.), Hurricanes and Typhoons: Past, Present and Future, Columbia University Press, New York, pp. 121-148.

Mock, C.J. (2008), "Tropical cyclone variations in Louisiana, U.S.A., since the late eighteenth century", Geochemistry, Geophysics, Geosystems, Vol. 9 No. 5, available at:https://doi.org/10.1029/2007GC001846.

Mock, C.J. (2017), "The temporal memory of major hurricanes", Cultural Histories, Memories and Extreme Weather: A Historical Geography Perspective, Routledge, London, pp. 78-92.

Monteil, C., Barclay, J. and Hicks, A. (2020), "Remembering, Forgetting, and Absencing Disasters in the Post-disaster Recovery Process", International Journal of Disaster Risk Science, Beijing Normal University Press, available at:https://doi.org/10.1007/s13753-020-00277-8.

Morgan, R.A. (2017), "On the home front", Cultural Histories, Memories and Extreme Weather, Routledge, London, pp. 34-54.

NDRRMC. (2015), "National Disasters Scheme", National Policy Document, Port Louis.

Nunn, P.D. (2018), The Edge of Memory: Ancient Stories, Oral Tradition and the Post-Glacial World, Bloomsbury Sigma, London, available at:

https://research.usc.edu.au/vital/access/manager/Repository/usc:27571 (accessed 30 November 2018).

O'Brien, G., O'Keefe, P., Gadema, Z. and Swords, J. (2010), “Approaching disaster management through social learning", Disaster Prevention and Management: An International Journal, Emerald Group Publishing Limited, Vol. 19 No. 4, pp. 498-508.

O'Keefe, P., Westgate, K. and Wisner, B. (1976), "Taking the naturalness out of natural disasters", Nature, Vol. 260 No. 5552, pp. 566-567.

Oliver-Smith, A. (1996), "ANTHROPOLOGICAL RESEARCH ON HAZARDS AND DISASTERS”, Annual Review of Anthropology, Vol. 25 No. 1, pp. 303-328.

Oliver-Smith, A. and Hoffman, S.M. (1999), The Angry Earth : Disaster in Anthropological Perspective, Routledge, London, available at:https://doi.org/10.1108/dpm.2000.07309cad.004.

Padya, B.M. (1989), The Climate of Mauritius, Second Edition, Mahatma Gandhi Institute, Port Louis, available at:

https://books.google.co.uk/books/about/The_Climate_of_Mauritius.html?id=qFkLAQAAIAAJ\&r edir_esc=y (accessed 12 March 2017).

Padya, M. (1976), Cyclones in Mauritius, Mauritius Printing., Port Louis.

Palutikof, J.P., Agnew, M.D. and Hoar, M.R. (2004), "Public perceptions of unusually warm weather in the UK: Impacts, responses and adaptations", Climate Research, Vol. 26 No. 1, pp. 43-59.

Perry, R.W. and Quarantelli, E.L. (2005), What Is a Disaster? : New Answers to Old Questions, Xlibris, Bloomington.

Pescaroli, G. and Alexander, D. (2015), "A definition of cascading disasters and cascading effects : 
Going beyond the toppling dominos metaphor", GRF Davos Planet@Risk, Vol. 3 No. 1, pp. 5867.

Pfister, C. (2011), "The Monster Swallows You", Disaster Memory and Risk Culture in Western Europe, RCC Occasional Report.

Pfister, C., Brazdil, R. and Barriendos, M. (2002), "Reconstructing past climate and natural disasters in Europe using documentary evidence", Climatic Change, Vol. 43, pp. 55-110.

Pfister, C., Garnier, E., Alcoforado, M.J., Wheeler, D., Luterbacher, J., Nunes, M.F. and Taborda, J.P. (2010), "The meteorological framework and the cultural memory of three severe winter-storms in early eighteenth-century Europe", Climatic Change, Vol. 101 No. 1, pp. 281-310.

Pridham, C. (1849), An Historical, Political, and Statistical Account of Mauritius and Its Dependencies, $\mathrm{T}$ and $\mathrm{W}$ Boone, London.

Rohland, E. (2015), "Hurricanes in New Orleans: Disaster Migration and Adaptation, 1718-1794", in Sommer, B. (Ed.), Cultural Dynamics of Climate Change and the Environment in Northern America, 1st ed., Brill, Leiden, pp. 137-158.

Rohland, E. (2018), "Hurricane Katrina and the Future of the Past", Changes in the Air: Hurricanes in New Orleans from 1718 to the Present, Burghan books, Oxford, p. 263.

Rouphail, R.M. (2019), Cyclonic Ecology: Sugar, Cyclone Science, and the Limits of Empire in Mauritius and the Indian Ocean World, 1870s-1930s, Isis, Vol. 110, available at: https://www.journals.uchicago.edu/doi/10.1086/702729 (accessed 31 July 2019).

Rouphail, R.M. (2020), "ESSENTIALLY CYCLONIC:" RACE, GENDER, AND DISASTER IN MODERN MAURITIUS, University of Illinois, available at: https://core.ac.uk/download/pdf/238434083.pdf (accessed 10 May 2020).

Santayana, G. (1905), The Life of Reason: Reason in Common Sense., Constable and Company, London.

Schenk, G. (2015), "'Learning from History'? Chances, problems, and limits of learning from historical natural disasters", in Kruger, F., Bankoff, G., Cannon, T., Orlowski, B. and Schipper, E. (Eds.), Culture and Disasters: Understanding Cultural Framings in Disaster Risk Reduction, Routeledge, London, pp. 72-88.

Schenk, G.J. (2007), “Historical disaster research. State of research, concepts, methods and case studies", Historical Social Research, Vol. 32 No. 3, pp. 9-31.

Shaw, S. (2014), "Black Swans are Red Herrings", 17th Annual International Symposium, TEES, College Station, Texas, p. 1.

Simpson, E. and Corbridge, S. (2006), "The geography of things that may become memories: The 2001 earthquake in Kachchh-Gujarat and the politics of rehabilitation in the prememorial era", Annals of the Association of American Geographers, Vol. 96 No. 3, pp. 566-585.

Taub, L. (2003), Ancient Meteorology, Ancient Meteorology, Taylor \& Francis, London, available at:https://doi.org/10.4324/9780203634288.

Titz, A., Cannon, T., Krüger, F., Titz, A., Cannon, T. and Krüger, F. (2018), “Uncovering 'Community': Challenging an Elusive Concept in Development and Disaster Related Work", Societies, Vol. 8 No. 3, p. 71.

Vaghjee, R.R. and Yan, M.L.M. (2003), "Improving the Tropical Cyclone Warning System and its Effective Dissemination in Mauritius", Early Warning Systems for Natural Disaster Reduction, Springer, Berlin, pp. 209-211.

Walshe, R.A. and Nunn, P.D. (2012), "Integration of indigenous knowledge and disaster risk reduction: A case study from Baie Martelli, Pentecost Island, Vanuatu", International Journal of Disaster Risk Science, Vol. 3 No. 4, pp. 185-194.

Walter, A. (1914), "Climate of Mauritius", in Macmillan, A. (Ed.), Mauritius Illustrated: Historical and Descriptive, Commercial and Industrial, Facts, Figures and Resource, p. p188.

White, G. (1974), Natural Hazards, Local, National, Global, Oxford University Press, Oxford, available at: http://repositories.tdl.org/tamug-ir/handle/1969.3/27281 (accessed 23 May 2017).

Wisner, B. (1993), "Disaster vulnerability: Scale, power and daily life", GeoJournal, Vol. 30 No. 2, pp. 
127-140.

Wisner, B., Blaikie, P., Cannon, T. and Davis, I. (2004), AT RISK Natural Hazards, People's Vulnerability and Disasters, 2nd ed., Routledge, London.

\section{Acknowledgments}

The authors wish to thank and acknowledge the interview partici- pants, the assistance of the National Archive and National Library staff in Mauritius, research assistants Vasishth Rajcoomar, Sharon Ram- sawmy, Tarun Seetah, and Priya Doya and Jacques Pougnet for his kind assistance, as well as Lauren Koerner for assistance with GIS.

\section{Funding statement}

This research was conducted as part of a studentship funded by the UK Natural Environment Research Council (NERC) grant number NE/L002485/1. 